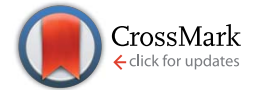

Cite this: RSC Adv., 2016, 6, 1076

Received 28th October 2015 Accepted 11th December 2015

DOI: 10.1039/c5ra22620a

www.rsc.org/advances

\section{The degradation of mechanical properties in polymer nano-composites exposed to liquid media - a review}

\begin{abstract}
Mohd Shahneel Saharudin, ${ }^{\text {ab }}$ Rasheed Atif, ${ }^{\text {b }}$ Islam Shyha ${ }^{\mathrm{b}}$ and Fawad Inam*b
The advancement of polymer nano-composites has been motivated by the need for materials with a specific combination of mechanical properties beyond those achieved from only one material. Integration of reinforcement into polymers at the nanoscale can provide a significant increase in numerous physical and mechanical properties of polymer nano-composites. However, in applications where contact with liquid media is unavoidable, the mechanical properties of polymer nano-composites suffer degradation which is a commonly observed phenomenon. Non aggressive liquid such as water is capable of lowering the mechanical properties of polymer nano-composites by acting as plasticizers while moderate and severe aggressive liquid when combined with residual stresses can cause unexpected brittle failure known as ESC. To date, only a few studies are reported discussing the ability of nano-fillers to resist degradation of mechanical properties in polymer nano-composites when exposed to liquid media. In this review, various factors responsible for mechanical property degradation caused by liquid media in polymer nano-composites and their remedies are studied.
\end{abstract}

\section{Introduction}

Integration of reinforcement into polymers at the nanoscale can provide a significant increase in numerous physical and mechanical properties of polymer nano-composites. ${ }^{1-5}$ The high strength to weight ratio of polymer nano-composites and their ability to exhibit flexibility by manipulating their mechanical properties are

${ }^{a}$ Universiti Kuala Lumpur Institute of Product Design and Manufacturing (UniKL IPROM), 56100 Cheras, Kuala Lumpur, Malaysia

${ }^{b}$ Department of Mechanical and Construction Engineering, Faculty of Engineering and Environment, Northumbria University, Newcastle upon Tyne NE1 8ST, UK. E-mail: fawad.inam@northumbria.ac.uk; Tel: +44 (0)1912273741 the main reasons attracting the interest of researchers and extensive research has been dedicated to this field in the past couple of decades. ${ }^{6,7}$ The mechanical properties of polymers can be modified by using numerous fibres and particulates and the small-sized nano-fillers have surpassed the large-sized reinforcements. ${ }^{\mathbf{8 - 1 0}}$

There are many applications in which polymer nanocomposites are either directly or indirectly exposed to certain liquid media conditions. The main drawback of polymeric materials is the loss of inherent mechanical properties caused by exposure to liquid media, such as marine environments, where the properties of polymers are strongly influenced by the seawater having a medley of various salts. ${ }^{11-14}$

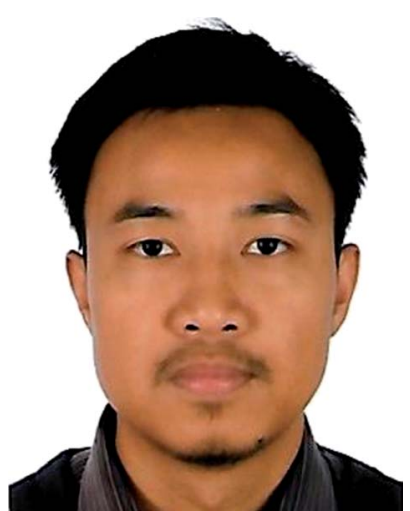

Mohd Shahneel Saharudin has been lecturer at the Institute of Product Design and Manufacturing, Universiti Kuala Lumpur Malaysia (UniKL IPROM) since March 2010. Saharudin obtained his BEng (Hons.) in Mechanical Engineering from Newcastle University in 2007 and MSc in Mechanical Engineering from Northumbria University in 2009. His research interest is in the polyester/halloysite nanocomposites.

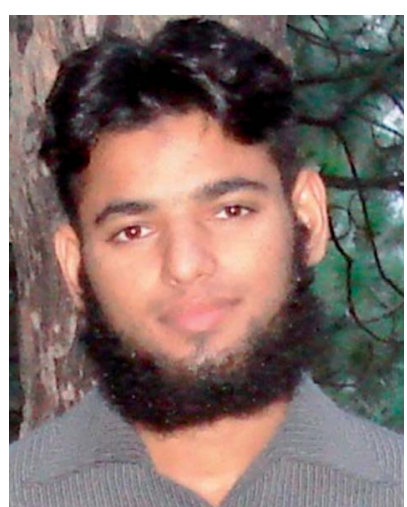

Rasheed Atif received his $B$. Sc. (Hons.) in Materials Engineering from UET Lahore in 2010 and $M S$ in Materials Engineering from GIK Institute in 2012. His research interests include the study of damage tolerance and fracture toughness of carbon nanotubes and graphene reinforced polymer nanocomposites. He has also extended the use of carbon nanotubes to composite field hockey sticks and other sports applications. 
Similarly, organic liquids can cause cracking at very low stress levels in semi-crystalline, amorphous, and high crosslinking polymers. ${ }^{15-17}$ In the last few years, the effect of water or chemical medium on the mechanical properties of thermosets were studied particularly in the field of piping, marine, medical, coating and automotive industries. ${ }^{18-24}$ For example, unsaturated polyesters are brittle due to their high cross-linking level and vulnerable to stress cracking failure and degradation in mechanical properties in applications where contact with liquid is unavoidable. ${ }^{25}$

Immersion or direct contact with fluid medium as in case of bottles, vessels, and pipes are the common sources of fluid contact that can cause degradation in mechanical properties. $^{24,26}$ Depending on their applications and type of fluids involved, primary source of fluid contact will definitely accelerate the stress cracking failure of polymers. In some cases, there is also source of secondary fluid contact, usually through detergents, lubricants, paints and coatings. ${ }^{27}$

Although various review articles are available on mechanical properties of polymer nano-composites, however, no article is yet published to the best of our knowledge where mechanical properties of polymer nano-composites are correlated with the liquid media and their influence on stress-cracking properties of polymer nano-composites. Therefore, this review article discusses in detail about how the polymer nano-composites behave in the presence of liquid media and rationale behind their peculiar behaviour.

\section{Liquid media and polymer degradation}

The in-service degradation of mechanical properties of polymers is an important aspect which limits the applications of these versatile materials. ${ }^{28}$ Polymer degradation is the deterioration in the properties caused by environments and service conditions, and normally limits service lifetime. ${ }^{29,30}$ Polymer degradation and failure caused by liquid medium can cause life threatening accidents. In 1996, a baby was fed via a Hickman line and suffered an infection, when new connectors were used by a hospital. ${ }^{31}$ The reason behind this infection was the cracking and erosion of the pipes from the inner side due to contact with liquid media. It was reported that the baby suffered from brain damage and later the mother decided to file a legal case of medical negligence (usage of inappropriate medical device) in 2002. ${ }^{31}$ Fig. 1 shows Hickman IV line fitted with polycarbonate (PC) connector composed of polycarbonate which undergoes brittle failure. This type of brittle failure caused by environmental stress cracking (ESC) can be life threatening to patients vulnerable to infections. As alternative, poly(methyl methacrylate) (PMMA) is also used when transparency is required. Both PC and PMMA are prone to ESC failure due to their molecular chain structure that can be easily disentangled when subjected to stress and liquid media. Since the applications in medical devices are vital, any crack or damage will be life threatening to users. Fig. 2 shows macrograph of brittle cracks from gate in male luer of connector. ${ }^{31}$ It can be observed that the cracks exist in male luer of connector as a result of stress cracking failure after exposure to liquid media in the hospital. Although in certain cases the secondary fluid contact is less severe than that with primary fluid contact, however, both can lead to catastrophic failure and degradation of the polymer properties. For instance, moulded polystyrene eyes for teddy bears became 'milky' as the subject underwent cataracts. ${ }^{27}$ In another example, failure of polyethylene after exposure to liquid media has been identified and reported in several publications. ${ }^{32-34}$ There are various automotive

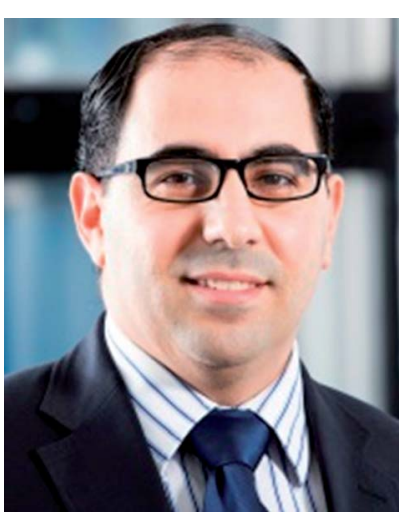

Dr Islam Shyha joined Mechanical and Construction Engineering Department, Northumbria University in January 2013. His research interests are in the field of advanced manufacturing technology including machining of composite and super-alloy materials for aerospace and automotive applications. $\mathrm{He}$ also provides consultancy for local and national engineering companies as well as fosters collaboration with industrial partners in order to ensure that cutting edge technology is transferred to our students. Dr Shyha has got a track record of research on the advanced machining with results and outcomes disseminated in the form of research papers published in peer reviewed journals; and international conference presentations. Dr Shyha also leads a postgraduate distance learning programme in Pipeline Integrity Management and Pipeline Engineering.

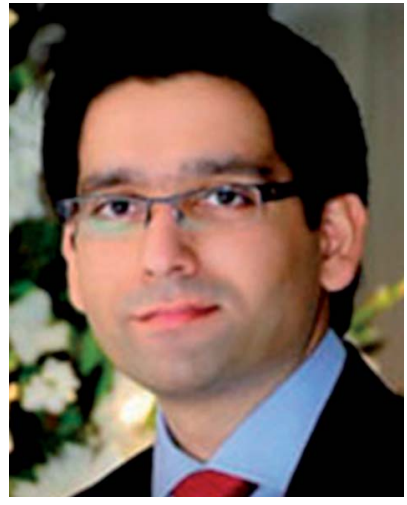

Dr Fawad Inam is the Director of Mechanical Engineering at Northumbria University in Newcastle upon Tyne, UK. His research is on the development of advanced materials including nanomaterials filled with fullerenes. He has worked with numerous aerospace, petroleum, manufacturing, defence and subsea industrial organisations. His expertise includes materials physics and chemistry, processing, characterisation, performance evaluation, applications, materials sustainability and technology commercial exploitation. Dr Inam has produced several high impact publications and authored more than 75 papers in peer-reviewed scientific journals and proceedings to date. He was the founding editor of journal "Epoxy" and on the editorial boards of various journals. 


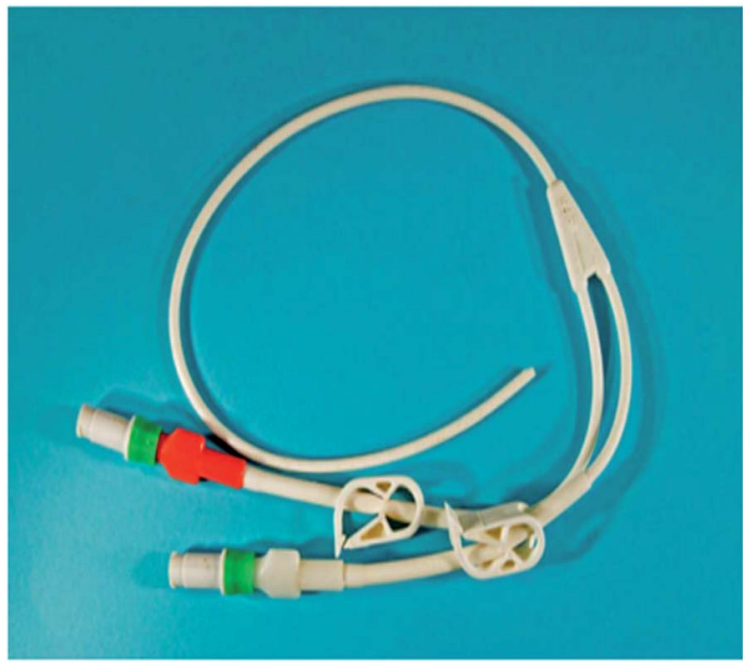

Fig. 1 Hickman IV line with fitted with polycarbonate connector. ${ }^{31}$

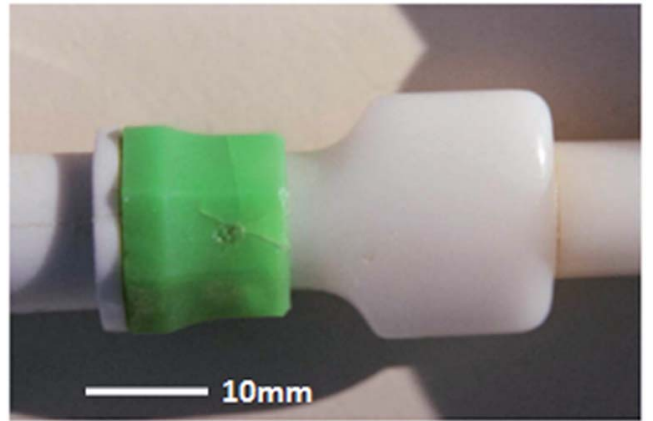

Fig. 2 Macrograph of brittle cracks from gate in male luer of connector. ${ }^{31}$

components made of polymers which undergo degradation when exposed to liquid media such as mirror housing, headlight lens, latch handle and ignition module. ${ }^{22} \mathrm{Fig} .3$ and 4 show the cracked mirror housing and headlight lens. Fig. 5 shows an SEM image of the headlight lens with an intersecting network of cracks which indicates that the lens underwent brittle fracture.

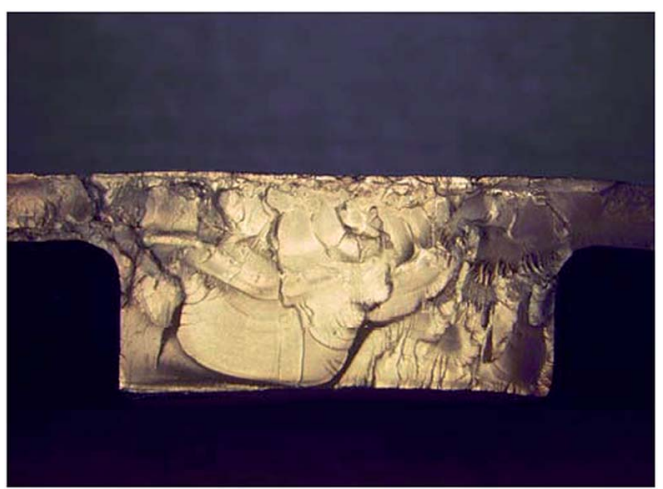

Fig. 3 Mirror housing exhibit stress cracking failure after liquid medium exposure.22

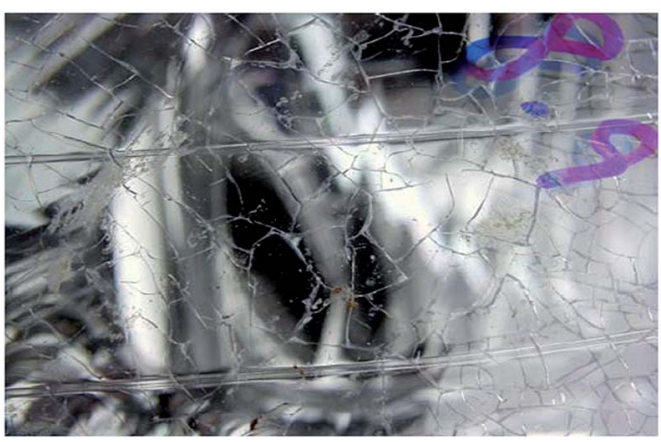

Fig. 4 Liquid medium effect on the headlight lens. ${ }^{22}$

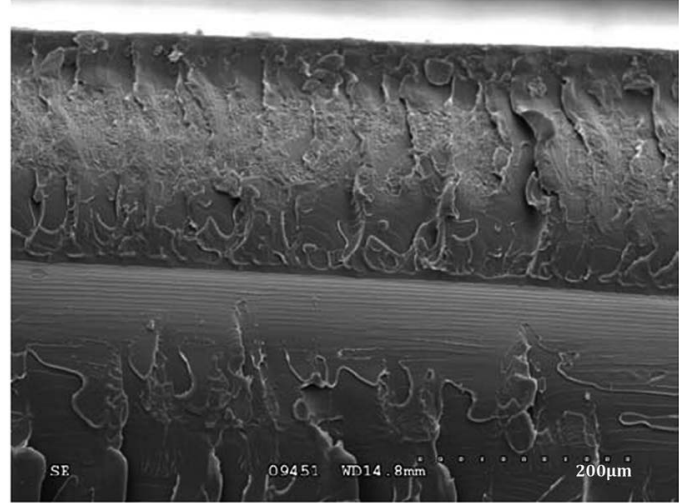

Fig. 5 SEM image of intersecting network of cracks on the headlight lens. $^{22}$

\section{Fibre and particle reinforcement}

Fibre and particulate reinforcements are commonly used to improve the mechanical properties of polymers. ${ }^{35-39}$ It has been shown that fibrous reinforcement shows a greater ability to resist crack propagation than particulate reinforcement. ${ }^{40-44}$

\subsection{Polymers reinforced with conventional and natural fibres}

Conventional fibres or synthetic fibres such as carbon fibre, glass fibre, Aramid and Kevlar are widely used in various engineering applications. ${ }^{45-51}$ High stiffness and excellent strength properties are two important factors that make the applications of these fibres favourable. Natural fibres with their long history of serving mankind are very important in a wide range of applications, and they compete and co-exist in the twenty-first century with man-made fibres, especially as far as quality, sustainability and economy of production are concerned. The applications, advantages, and drawbacks of both types of fibres are illustrated in Fig. 6. Carbon fibre, glass fibre, Aramid and Kevlar are high strength fibres and have found many applications such as aerospace, construction, automotive, sports, marine and pipes. ${ }^{52}$ Carbon fibres which were developed in the United Kingdom in 1960s are widely used as reinforcement in polymer nano-composites ${ }^{53}$ and are recognized for their high 
strength (3.5 GPa). However, they show a high degree of brittleness having Young's modulus around $143 \mathrm{GPa}$ and when they are used as reinforcement in polymers, the properties of composite system are highly propitious and currently carbon fibre-polymer composite systems are extensively used in automotive, aerospace, sporting goods and textiles. ${ }^{54-59}$ Glass fibre is another fibrous reinforcement which is extensively used to produce polymer composite materials. One of the factors which led to widespread application of glass fibre was the invention of proper heating and cooling technology which allowed its mass production. ${ }^{60,61}$ The fibre sizing is the most important component in the manufacturing process of a glass fibre. ${ }^{62}$ It is the most common type of reinforcement in polymers due to its low cost and superior mechanical properties. ${ }^{63,64}$ Recently, graphene has fascinated academic and industrial interest since it can produce a remarkable improvement in properties at very low content. $^{\mathbf{6 5 , 6 6}}$ Graphene has found applications in electronics devices, energy storage, sensors, and biomedical applications. ${ }^{67-72}$ Graphene may be preferred over other conventional fillers owing to its high surface area, tensile strength (TS), thermal conductivity and electrical conductivity. ${ }^{73-78}$ In the past, carbon nanotubes (CNTs) gained much attention due to their superior mechanical, thermal, and electrical properties. ${ }^{79-83}$ Moreover, CNTs have been broadly used in a range of applications such as biomedical, structural, electrical circuits, actuators, hydrogen storage and many more ${ }^{\mathbf{8 4 - 8 7}}$ The dispersion state of CNTs and interfacial interactions are most important parameters in CNTs-polymer nano-composites. ${ }^{\mathbf{8 8 - 9 4}}$

It is widely believed that using nanofillers, such as CNTs, graphene, and nanoclay, the mechanical properties of polymers can be improved to extreme values. However, the reported values do not reflect the expected level of improvement which

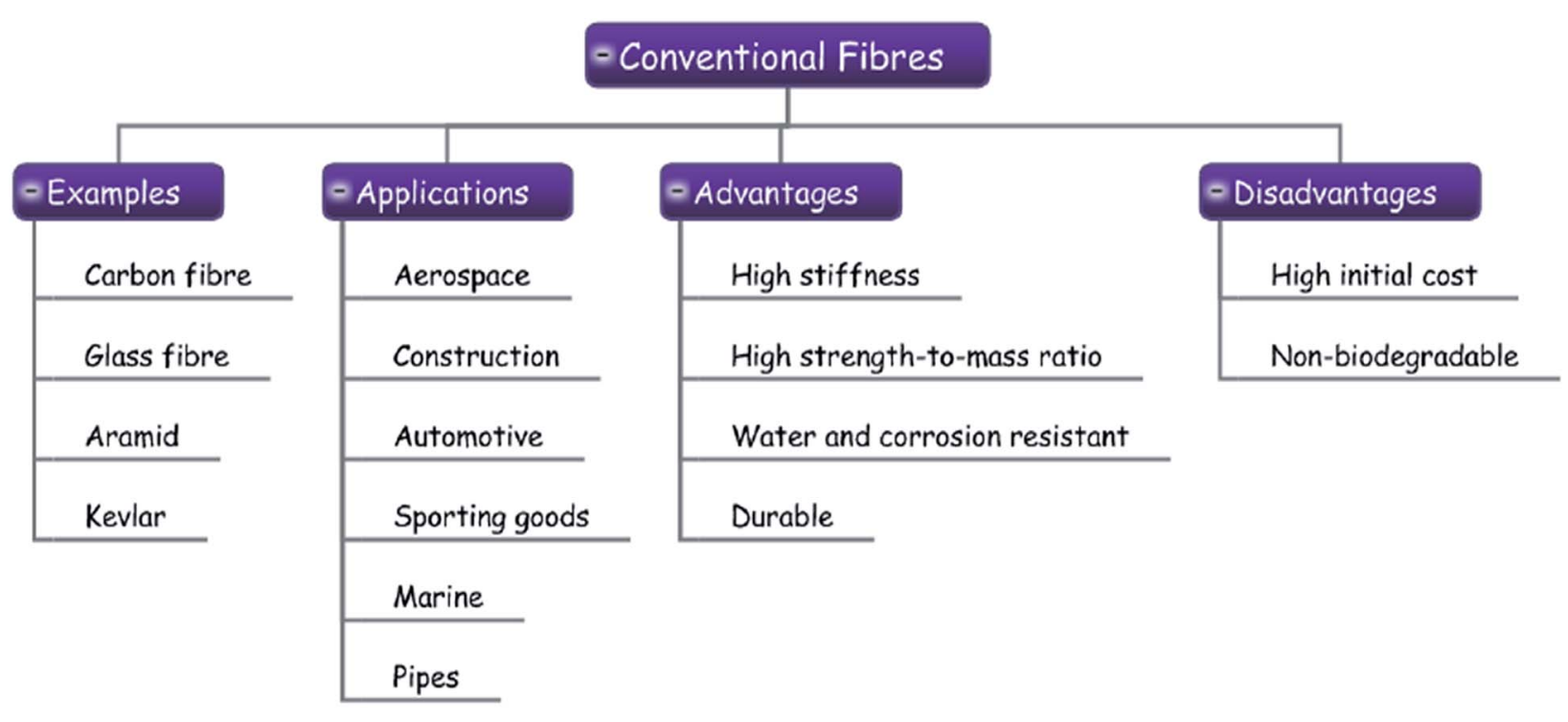

- Natural Fibres

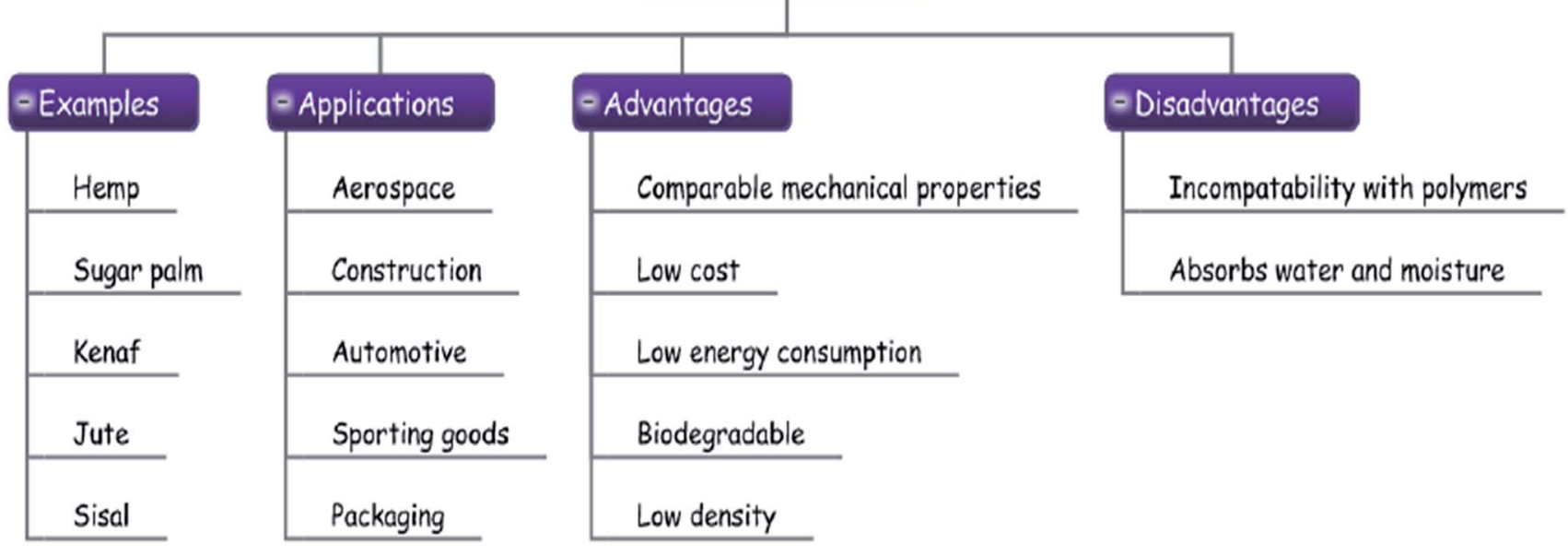

Fig. 6 Characteristics of conventional fibres and natural fibres from literatures. 
can be attributed to poor dispersion state of the filler, agglomerates which act as stress raisers, and weak interfacial interactions. Schaefer and Justice have studied in detail the polymer nanocomposites and reported the presence of large-scale disorder that is common in nanocomposites regardless of the level of dispersion, leading to substantial reduction in mechanical properties. ${ }^{95}$ They further reported that even in nanocomposites, microscale structures are present which significantly influence the mechanical properties of nanocomposites.

Over the last two decades, natural fibres are evolving as better option to replace the conventional fibres in many applications. $^{96}$ Natural fibres are produced by using traditional manufacturing techniques such as resin transfer moulding, vacuum infusion, injection moulding and many more. ${ }^{96}$ Natural fibres such as hemp, ${ }^{97,98}$ sugar palm, ${ }^{99-102}$ coir, sisal and jute $^{\mathbf{1 0 3 - 1 0 5}}$ have attracted researchers to extend their usage in civil engineering applications. ${ }^{106-112}$

\subsection{Particulates reinforced polymers}

The interest in particulate reinforced polymer nano-composites has significantly increased and first particulate reinforced polymers used mineral particles as fillers. ${ }^{53}$ Some of the earliest work on inorganic toughening was achieved in 1987 at Toyota. ${ }^{113-115}$ The particulate reinforcements can improve the stiffness, creep resistance and fracture toughness of polymers. ${ }^{116,117}$ Evidently, it was observed that mechanical properties of polymer nanocomposites are influenced by several factors such as shape, size, aspect ratio and the dispersion quality of reinforcing particles. ${ }^{118-125}$ The mineral particles were first used as cheap fillers and additives since conventional polymers were first created. For example, talc and mica from silicate-based minerals with layer-type structures were used in the form of thin platelets. ${ }^{53}$ The nano-composites produced using mineral particles are easy to process and allow higher filler content and cause significant increase in stiffness and strength of polymers. ${ }^{53}$ In the development of polymer nano-composites, the incorporation of nano-particles has been widely investigated employing numerous experimental setups and research methods. ${ }^{126-128}$ Other materials used in nano-reinforcement of polymers are layered silicates and ceramic nano-particles such as $\mathrm{SiO}_{2}, \mathrm{TiO}_{2}$ and $\mathrm{CaCO}_{3} \cdot{ }^{129-131}$ Addition of layered silicate to natural rubber and polyurethane were found to improve stiffness and strength. ${ }^{\mathbf{1 3 2}}$ Apart from that, it has conclusively been shown that the Young's modulus of nano-composites escalated five times with the silicate based reinforcements. ${ }^{133}$

Table 3 shows prominent studies that have been carried out using various types of fillers to improve mechanical properties of polymer based nano-composites.

\section{Effects of liquid media on mechanical properties of polymer nano-composites}

The following section discusses the effect of liquid exposure on mechanical properties of polymer nano-composites. In general, the liquid media can be classified into three categories; nonaggressive, moderate, and aggressive media. The polymers are more vulnerable to liquids with hydrogen bonding and are classified as aggressive media.

\subsection{Water}

Water has neutral $\mathrm{pH}$, due to its inherent hydrogen bonding; water can lower the mechanical properties of the composite by plasticizing the matrix and reducing the interfacial strength of the matrix and reinforcing additive. In real application, thermosets based polymers such as epoxy and unsaturated polyester also suffer mechanical properties degradation when exposed to water as in marine and automotive industries. ${ }^{18-22,134}$ The water may penetrate into the polymers and polymer nano-composites by capillary action and may significantly affect the polymer chains and interphase. ${ }^{\mathbf{1 3 5}}$

Table 1 shows some of the prominent researches that have been carried out to study the effect of water on mechanical properties of polymer composites. There is consensus in the reported literature that water can significantly degrade the properties of polymers and polymer nano-composites. Normally, the absorption rate increases with longer immersion time. The reaction between water molecules and polymer matrix causes deterioration of interphase which has a detrimental effect on the mechanical properties.

The primary reasons for the lower mechanical properties are, matrix swelling, interphase debonding, physical damage of the interphase, and hydrolysis of the material by water. ${ }^{\mathbf{1 4}}$ GarciaEspinel et $a .^{\mathbf{1 3 6}}$ have associated the reduction in tensile strength and flexural strength of epoxy/glass fibre with the water absorption and reaction between water and composite material. This finding was supported by other researchers as well. ${ }^{137-139}$

Rull et al. ${ }^{\mathbf{1 4 0}}$ were able to reduce the water absorption and increase the mechanical properties such as tensile and flexural strength of glass fibre-polyester through uniformly dispersed clay in the nano-composites. A small fraction of nano-clay was used to provide resistance towards humidity and liquid. If nanoclay is used more than $1 \mathrm{wt} \%$ it tends to agglomerate and consequently increases the water absorption and reduces mechanical properties. ${ }^{18}$ Table 2 shows the tensile strength of the nano-composites after certain period of immersion in water. It can be seen that the breaking strength and tensile stress significantly reduced as the nano-composites suffer physical damage.

Huang and Sun, ${ }^{\mathbf{1 4}}$ in their study demonstrated that water was found to cause delamination between fibre and matrix after water immersion. They found that the tensile strength of glass/ polyester composites was decreased as a result of hydrolysis of the material and physical damage of interphase. This was caused by polymer debonding between matrix and glass fibre. Fig. 7 and 8 show the SEM images of broken samples before and after water immersion. It was examined that delamination between the fibre and matrix occurred which explains the reduction in tensile strength of the glass/polyester nano-composites. ${ }^{\mathbf{1 4}}$

Ishak et al. ${ }^{\mathbf{1 0 2}}$ studied Arenga pinnata (sugar palm) fibre resistance to seawater. It was shown that natural fibre from 
Table 1 Some prominent literature on the effect of water on the properties of polymer nano-composite

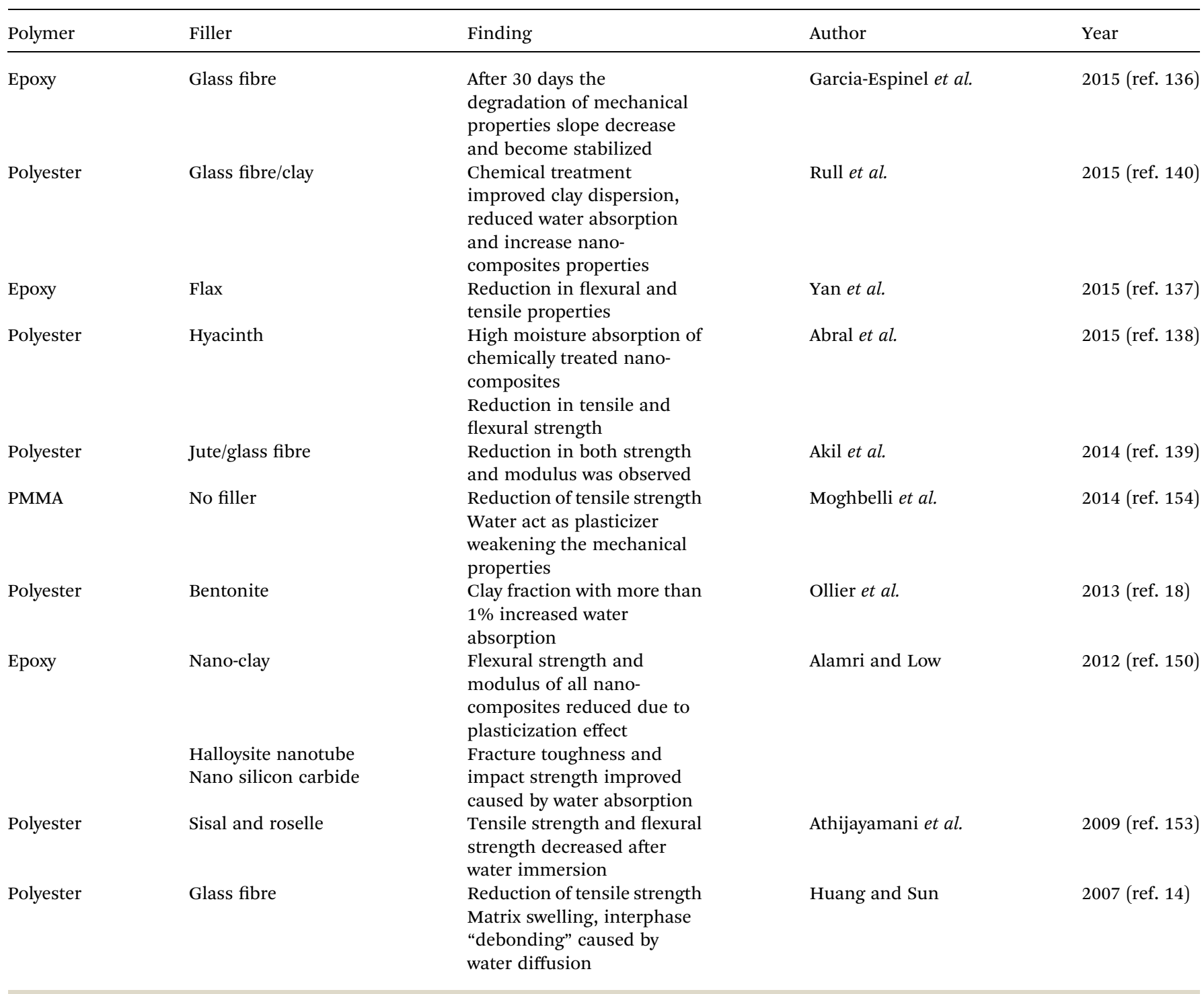

sugar palm reinforced polymers showed improved mechanical properties and high resistance against seawater. ${ }^{101}$ Sugar palm trunk recorded lowest seawater absorption $(0.39 \%) .{ }^{\mathbf{1 0 2}}$ Nonetheless, this material (Arenga pinnata) remains unknown by many people due to limited information available. Since this material is biodegradable, it is compelling to investigate whether it has the capabilities to be used as an environmental stress cracking resistor in polymers.

Table 2 Tensile strength of glass/polyester at different water immersion period ${ }^{14}$

\begin{tabular}{llll}
\hline $\begin{array}{l}\text { Immersion time } \\
\text { (day) }\end{array}$ & $\begin{array}{l}\text { Breaking strength } \\
(\mathrm{N})\end{array}$ & $\begin{array}{l}\text { Tensile stress } \\
(\mathrm{MPa})\end{array}$ & $\begin{array}{l}\text { Elongation at } \\
\text { break }(\%)\end{array}$ \\
\hline 0 & 3246.77 & 192 & 3.11 \\
7 & 3098.26 & 181 & 3.07 \\
14 & 3002.96 & 176 & 3.27 \\
21 & 2754.11 & 162 & 3.15
\end{tabular}

Joseph et al. ${ }^{\mathbf{1 4 1}}$ have shown that sisal fibre reinforced polypropylene nano-composites when exposed to water, underwent interfacial failure that can be attributed to plasticisation caused by water which degraded the fibre-matrix interfacial interactions. Zainuddin et al. ${ }^{\mathbf{1 4 2}}$ have shown that mechanical properties of nano-clay filled epoxy nano-composites degraded when exposed to water with a direct relationship to exposure time and temperature. It was found that $2 \mathrm{wt} \%$ nano-clay reinforcement showed optimum mechanical properties compared to neat epoxy. This finding is in agreement with other researchers. ${ }^{\mathbf{1 4 3 - 1 4 8}}$

Dhakal et $a l^{98}$ produced hemp-polyester nano-composites and studied the effect of water on the mechanical properties of produced nano-composites. They observed that water uptake increased with increasing volume fraction of the fibres. Fig. 9 shows the tensile stress of for hemp fibre-polyester. The tensile stress increased $22 \%$ for 2 layer hemp fibre after water immersion. The tensile stress was decreases $38 \%$ and $15 \%$ for 3 and 4 layer reinforced hemp. For 5 layer hemp, the tensile stress was found higher than specimens tested in air. The gap between 


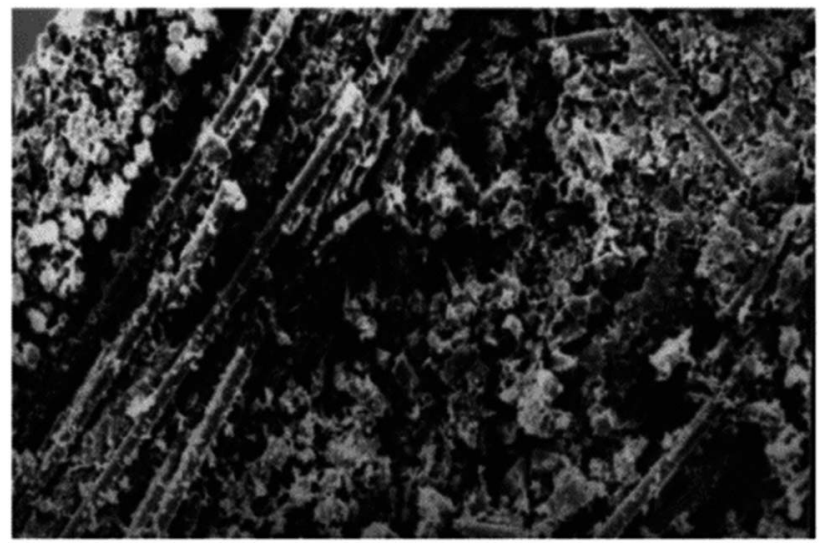

Fig. 7 Broken section of glass/polyester composite sample without water exposure. ${ }^{14}$

fibre and polymer probably filled by the water therefore lead to the improvement of tensile properties as also reported in other literature. ${ }^{149}$ Fig. 10 shows the flexural strength of the composites. Water absorption caused weak fibre-matrix interface which can be associated with the decrease in flexural stress.

Alamri and Low ${ }^{\mathbf{1 5 0}}$ produced nano-clay-epoxy and studied the swelling behaviour in water with time as shown in Fig. 10. They observed that weight gain decreases with increasing nanoclay content. Ollier et al. ${ }^{18}$ also reported a decrease in weight gain with increasing content of bentonite clay in polyester resin. The nano-clay acts as physical barrier and stops water molecules to penetrate through. ${ }^{151,152}$

In another major study by Athijayamani et al. ${ }^{153}$ found that water decreased the tensile and flexural strength of roselle reinforced polyester.

In comparison with unexposed composites, $7 \%$ tensile strength reduction was observed in case of $10 \mathrm{wt} \%$ roselle reinforcement. In case of $30 \mathrm{wt} \%$ of roselle reinforcement, the tensile strength was decreased to $11.7 \%$. Flexural strength of the composites also decreased when exposed to water. In case of $10 \mathrm{wt} \%$ of roselle, $5.7 \%$ of flexural strength reduction was

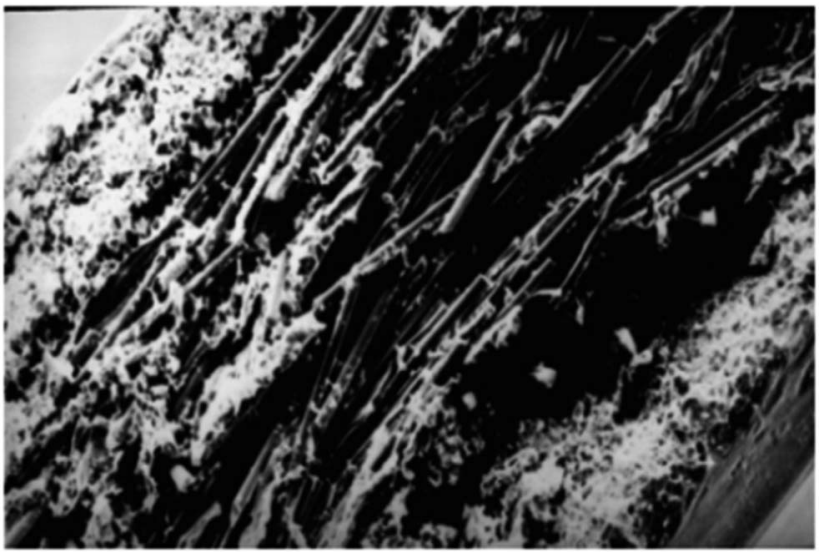

Fig. 8 Broken section of glass/polyester composite after 21 day immersion in water. ${ }^{14}$

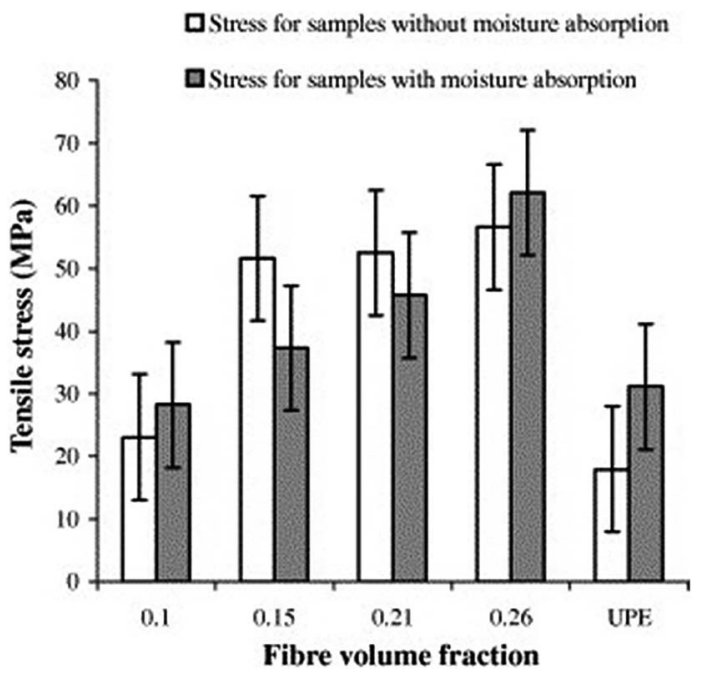

Fig. 9 The tensile stress of hemp fibre reinforced unsaturated polyester. ${ }^{98}$

observed. About $8.6 \%$ flexural strength was also found decreased with the water uptake by $30 \mathrm{wt} \%$ roselle/polyester composites. In this particular study, it can be observed that water reduced the tensile and flexural strength of the composites.

\subsection{Aggressive liquids}

In some applications, the contact with aggressive liquid media is inevitable such as automotive applications where the components are exposed to industrial chemicals (gasoline, windshield liquid and brake fluid). ${ }^{\mathbf{1 5 6}}$ Residual stresses are generated during injection moulding process to produce polymer components. These residual stresses when combine with aggressive liquid media can cause unexpected brittle failure. ${ }^{157-161}$ This phenomenon is known as environmental stress cracking (ESC) or sometimes described as environmental

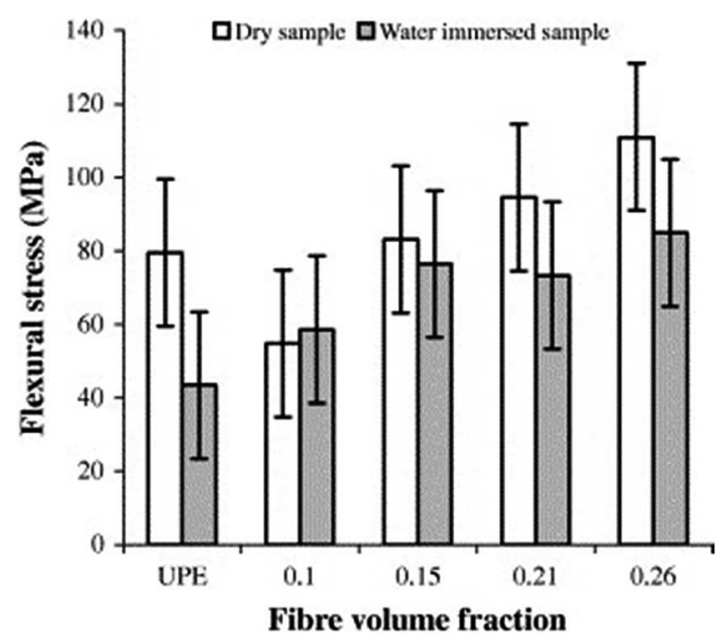

Fig. 10 The flexural stress of hemp fibre reinforced unsaturated polyester. ${ }^{98}$ 
assisted cracking. ${ }^{\mathbf{1 6 2 - 1 6 4}}$ It is defined by premature initiation of cracking and embrittlement of plastics as a result of concurrent action of stress and strain in contact with certain fluids. ${ }^{22,27}$ In simpler terms, it is a slow crack growth. ${ }^{164-168}$ As it involves liquids, therefore, it is also called as stress corrosion of polymer in solvents. ${ }^{169,170}$ For a given polymer, certain liquid media can cause ESC soon after they come in contact. Such liquid media are called as ESC agents for those polymers. In general, the liquid media with hydrogen bonding show a higher tendency to cause ESC in polymers and therefore care must be taken to avoid the contact with such liquid media. ${ }^{22,27}$

Table 3 shows the research conducted to study the influence of liquid media on the degradation phenomenon of polymer nano-composites. In general the work carried out can be divided into two main categories;

(a) The effect of liquid media on the engineering properties of polymer nano-composites.

(b) The influence of particles and fibres to resist stress cracking failure.

Based on literatures, it can be seen that many works have been carried out to study the effect of liquid media on environmental stress cracking failure of polymer nanocomposites.

\subsection{Mechanism of ESC}

The ESC typically takes place in amorphous polymers because of their loose structure which enables the fluids to permeate into the polymer. ${ }^{27,171}$ The amorphous thermoplastics have also shown high sensitivity to ESC. The locally dissolved aggressive liquid can cause crazing, cracking, and plasticization. ${ }^{172}$ Crazes are extended areas gathered by highly drawn fibrils which link the micro-cracks and stop their movement and combination. ${ }^{\mathbf{1 6 2}}$ Gent ${ }^{173}$ proposed that hypothetical mechanism of crazing is associated with the stress-activated devitrification of a small amount of material at the tip of a flaw to a softer rubbery state. This mechanism is similar to what has been reported by Knight. ${ }^{174}$ The following points can be drawn from the existing reported research on the mechanism of ESC.

(a) The application of hydrostatic pressure can stop the craze development. $^{173}$

(b) Temperature influences the crazing stress. Increasing the temperature up to $T_{\mathrm{g}}$ will reduce the craze and then level off. ${ }^{27}$

(c) The tensile stress at which crazes form is much lower in the presence of certain active liquids and vapours.

(d) Crazes do not develop in materials with prominent molecular orientation of the tension but develop when it is perpendicular to the tension. ${ }^{\mathbf{1 7 4}}$

Hansen pointed out that the solubility parameters have three categories of interconnected forces; dispersive, polar, and hydrogen bonding. ${ }^{27,175}$ The presence of hydrocarbon liquid can significantly influence the viscoelastic properties of biodegradable polymers. Widiastuti et al. ${ }^{176}$ reported that there is consistent decrease in modulus with an increase in hydrocarbon liquid content even at $40{ }^{\circ} \mathrm{C}$. In some cases, nonaggressive chemicals can also accelerate brittle failure. ${ }^{177}$ It was shown that the porosity in unsaturated polyester creates space between matrix and fibre. The porosity allows the liquid media to diffuse into the nano-composites which can create large internal stresses before failure takes place. ${ }^{\mathbf{9 8 , 1 4 4 , 1 7 8 , 1 7 9}}$

The ESC in polymers and nano-composites has also been studied for biomedical applications such as surgical, respiratory, drug delivery and IV access. ${ }^{\mathbf{1 8 0 - 1 8 3}}$ The glassy polymers such as polycarbonate and PMMA are extensively used for biomedical applications. Wright ${ }^{27}$ has shown that residual stresses during injection moulding process are responsible for causing ESC in polymers. The residual thermal stresses are also found in polymers arising from temperature gradients during the fabrication process. ${ }^{156}$ Isayev $^{\mathbf{1 8 4}}$ has revealed that the residual thermal stress is of parabolic shape with compression mode on the surface which shifts to tension mode in the core. A number of molecular mechanisms have been proposed responsible for ESC such as "interlamellar failure". ${ }^{\mathbf{1 8 5 , 1 8 6}}$

4.3.1 Organic solvents. The main characteristic of stress cracking agent is essentially identified by liquid diffusion through the craze fibril structure. ${ }^{163}$ Once the liquid penetrates to the craze tip, it then starts to plasticise the polymer and permits the craze to develop. The degree of absorption of a liquid media into polymer is a function of solubility parameters of the liquid and the polymer. ${ }^{175}$ The organic solvents can significantly deteriorate the mechanical properties of polymers. From the tensile tests performed, Alimi et al. ${ }^{187}$ have reported that elastic modulus of high density polyethylene (HDPE) decreased up to $64 \%$ when exposed to toluene and methanol for seven days. The toluene-methanol mixture was significantly reduced the structural integrity of the specimens. Moreover they also suggested that crystallinity gradients responsible for the poor mechanical properties. Dashtizadeh et al. ${ }^{188}$ observed the surface hardness, stress cracking resistance and glossiness of acrylic resin nano-composites under severe environmental conditions. They observed that mechanical properties significantly deteriorated when the samples were exposed to acetone and toluene as a result of liquid penetration into the matrix.

4.3.2 Detergent. Detergent like Igepal has been used in many studies involving environmental stress cracking. This liquid has been used widely to test the products durability in packaging and pipe application. ${ }^{189}$ This liquid has two significant effects:

(a) Accelerates crazing by plasticizing the amorphous region of the bulk polymer. ${ }^{166}$

(b) Accelerates fracture of the craze by plasticizing the crystalline region of the fibrils. ${ }^{\mathbf{1 6 2}}$

Exposure of polyethylene (PE) to stress cracking agents such as detergents will cause brittle fracture of PE under external loading. ${ }^{163,189}$ The crack development under ESC environment is shown in Fig. 11 where micro-cracks are first initiated which coalesce and cause brittle fracture under the influence of applied stress. ${ }^{\mathbf{1 5 6 , 1 9 0}}$ In thermoplastic polymers, the molecular chains are bonded via weak van der Waals forces or hydrogen bonding and exhibit high mobility hence easily disentangled when subjected to stress. This phenomenon is characterized by multiple cracks, smooth morphology, craze remnants, stretched fibrils, and alternating bands. ${ }^{22}$ When an amorphous, semicrystalline, and unsaturated polyester based product is in contact with a fluid, it can crack instantly or even break at low 
Table 3 Polymer and nano-composites exposed to different chemical environments

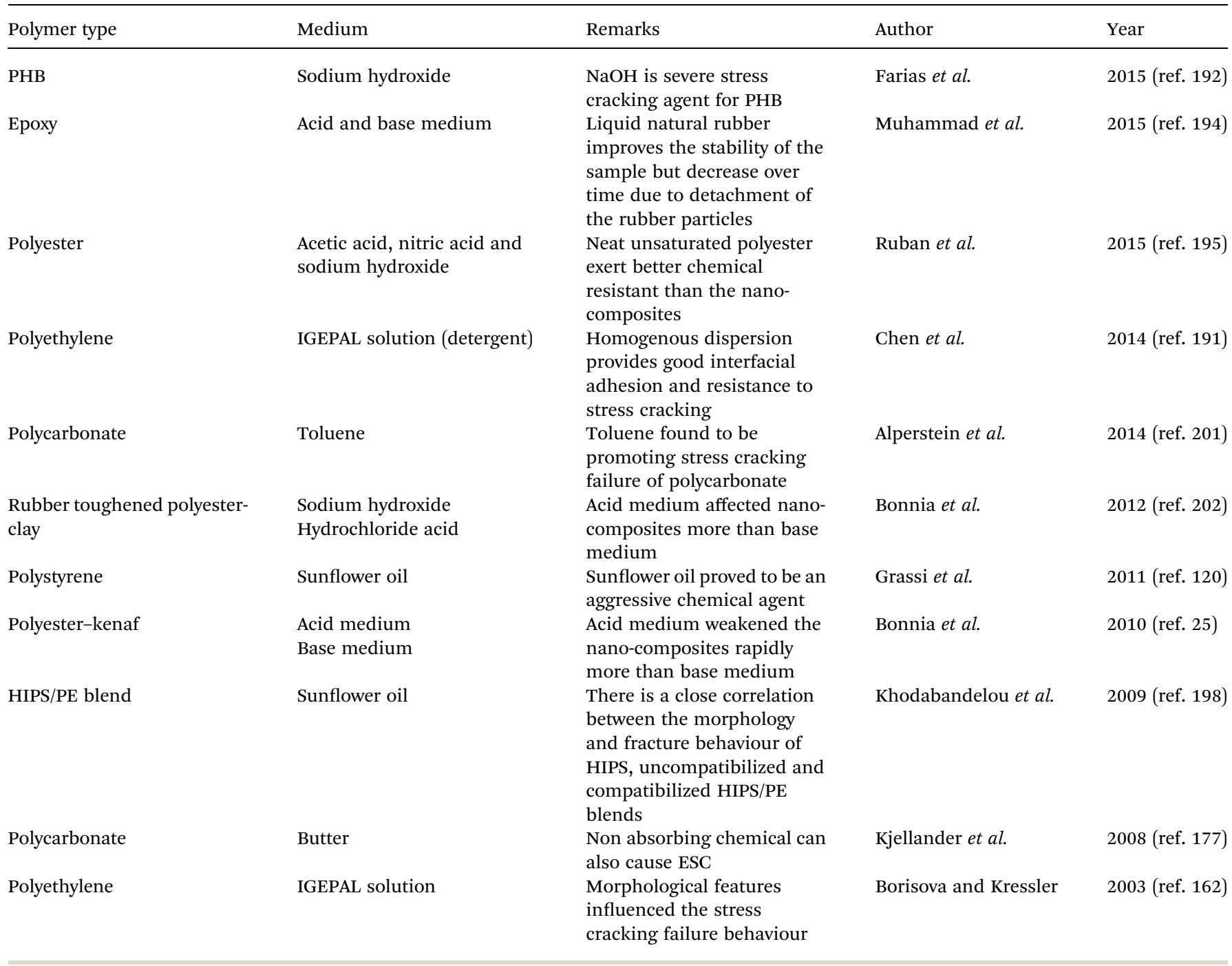

stress. Chen ${ }^{191}$ investigated the effect of Igepal CA 630 solution on HDPE/EVA (ethylene-vinyl acetate) and LDPE/EVA blends by using Bell Telephone test. The solution caused the detachment of EVA phase from the matrix. Stress concentration gives rise to cracking and formation of micro-pores inside the blend which produced higher stress concentration between the particles.

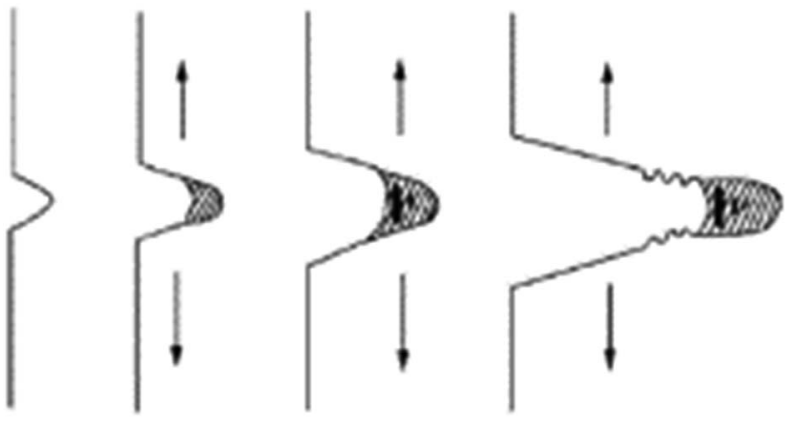

Fig. 11 Crack developments under ESC condition. ${ }^{155}$
The micro-porosity may hamper crack propagation as tip of the cracks is blunted when they come in contact with pores as shown in Fig. 12.

4.3.3 Acid medium. In most recent study by Farias et al., ${ }^{192}$ poly(3-hydroxybutyrate) (PHB) was immersed in sodium hydroxide $(\mathrm{NaOH})$ environment followed by tensile testing. The exposure of the sodium hydroxide did not significantly reduce the Young's modulus. Plasticization which normally softens the polymer structure did not occur as it can be seen to polymers exposed to water. However the significant effect of sodium hydroxide was observed on the tensile strength and strain at break. Compared to unexposed samples, $30 \%$ of tensile strength and $40 \%$ of strain were found decreased as a result of the sodium hydroxide exposure. In addition, when the samples tested in slower crosshead speed, the tensile strength reduced to $60 \%$ and the strain at break was reduced $70 \%$. The duration of liquid media exposure and stress facilitate crazes, cracking and disentangle molecular structure. ${ }^{193}$ Although ESC can occur in air, however, it is significantly increased in the presence of media. Farias et al. ${ }^{192}$ evidently shown that $\mathrm{NaOH}$ solution 


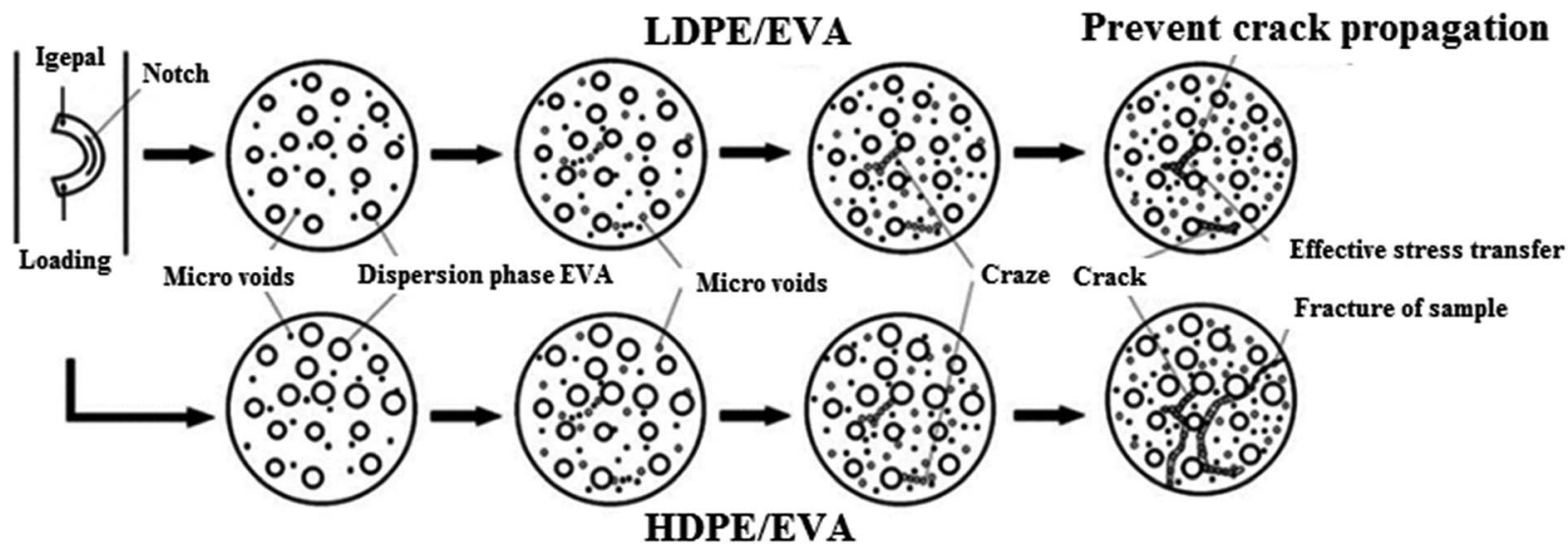

Fig. 12 The failure mechanisms of LDPE/EVA and HDPE/EVA blends. ${ }^{191}$

caused a significant deterioration in the mechanical properties of poly(3-hydroxybutyrate). Muhammad et al. ${ }^{194}$ in their study on mechanical properties of hybrid glass/kenaf fibre-reinforced epoxy. Their analysis showed that acid medium and base medium exposure towards epoxy/glass composites reduced the flexural and impact strength. This also accords with earlier observations by Bonnia et al. ${ }^{25}$ which discovered the effect of acid medium on rubber reinforced polyester/kenaf composites. They reported on the comparison of the stress values of composites over time to failure between dry and immersed specimens in acid medium. In general they agreed that when the polymer composites exposed to acid medium, the stress required to break the specimens was reduced compared to those tested in air. Ruban et al. have reported that unsaturated polyester (without reinforcement) showed higher resistance to liquid media (acetic acid, nitric acid, and sodium hydroxide) than when it was reinforced with nano-clay. ${ }^{195}$ The expanded clay caused polymer swelling in nitric acid and aqueous ammonia. From their chemical resistance investigations, the increased of clay content increased the liquid absorption. Fig. 13 depicts the crack growth under tensile stress in glass/ polyester in dilute $\mathrm{HCl}$ acid. Akdemir et al. ${ }^{169}$ showed that crack proceeds along fiber-matrix interface causing delamination. The dimensions of the samples change significantly because of liquid media, applied stress, crack growth and delamination. ${ }^{196}$ The physical effect of the environment on the glass/polyester nano-composites is indicated by liquid and gas absorption followed by the development of swelling at certain rate. Fibre/matrix debonding takes place due to swelling which subsequently increases internal stresses and results in loss of structural integrity. ${ }^{14,134,141,197}$ Compared to polymer matrix, the polymer-glass interface and the glass fibre reinforcement are considered to be more vulnerable to environmental degradation. ${ }^{40}$ ESC becomes feasible when the aggressive liquid diffuses through the polymer matrix via micro-cracks.

4.3.4 Sunflower oil and butter. Khodabandelou et al. ${ }^{198}$ studied the phenomenon of ESC in sunflower oil of HIPS/PE blends. The ESC resistant were analysed in tensile creep tests. Polyethylene (PE) was used to reinforce the composites. The first major finding indicates that the ESC resistant decreased with the addition of PE as a result of incompatibility between these two polymers. Another major finding which was observed from the morphological analysis suggested that, polymer matrix and PE particles were easily disentangled as a consequence of the weak bonding. Andena et al. ${ }^{17}$ reported on the high impact polystyrene (HIPS) bending properties exposed to sunflower oil. Before the bending test take place, all specimens were immersed in the sunflower oil for minimum one hour. The time of crack initiation and propagation was significantly reduced when the polymers in contact with the environment (sunflower oil). The fracture resistance also lower compared to HIPS samples tested in air. Grassi et al. ${ }^{120}$ studied the influence of rubber particles of high impact polystyrene (HIPS) in the sunflower oil and oleic mixture. Between these two liquid media, sunflower oil was found to be more aggressive ESC agent. Interestingly, small rubber particles reinforcement reduced the effect of ESC. It was found that HIPS samples with a lower fraction of small particles exhibited better resistance to sunflower oil. A number of studies have been carried out to enhance ESC resistance of numerous styrenic based polymeric materials. Incorporation of rubber particles into polystyrene was found to be an efficient method to

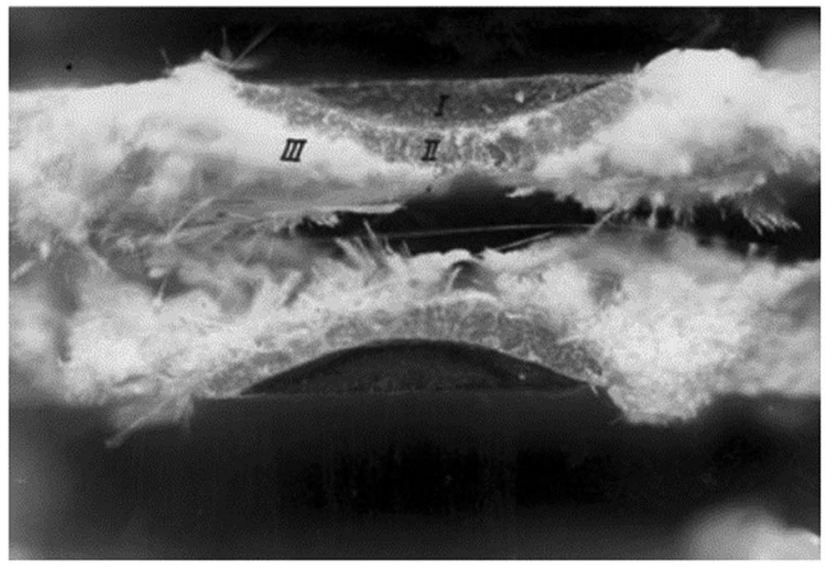

Fig. 13 Fractograph of stress corrosion crack growth of surface crack: ((I) starter notch; (II) stress corrosion crack growth; and (III) cracking in air brush like region). ${ }^{169}$ 
improve toughness. ${ }^{199,200}$ However further research needs to be carried out to study the effectiveness of rubber particles in reducing stress cracking failure caused by environment. Kjellander et al. ${ }^{177}$ exposed polycarbonate to butter and performed 3 point bend ESC testing. Non absorbing chemical like butter can cause ESC to polycarbonates. Butter was found to increase the amount of energetically favoured trans-trans conformation at the polycarbonate surface.

\section{Conclusions}

Undoubtedly, exposure to liquid media causes severe degradation of mechanical properties of polymers and polymer nanocomposites. The lowered mechanical properties and ESC are a major concern in the applications of polymers and polymer nano-composites in various applications such as medical, marine, automotive and coating industries. Non aggressive liquid such as water can act as a plasticizer if exposed to polymers for a certain period of time and also responsible for reduction in strength.

Swelling, plasticization, and detachment of fibre and particulate reinforcement from the matrix are commonly observed phenomena in polymer nano-composites when exposed to liquid media. Diffusion of liquid via micro-cracks leads to stress cracking which can be avoided by fibre and particulate reinforcement. It is interesting to study the stress cracking resistance of polymer nano-composites under external stresses because of complex phenomena happening simultaneously. ${ }^{168}$

The existing information is definitely inadequate and the lack of sufficient data makes it hard to predict the stress cracking failure of nano-particle reinforced polymers in the presence of liquid media. In that respect, research can be carried out by reinforcing polymer matrix with different fibres and particulates to determine the resistance of polymer nanocomposites toward ESC. The understanding of these mechanisms will contribute to the betterment of existing mechanical properties of polymers, particularly for application that are exposed to liquid media.

The nanocomposites have not fulfilled the expectations due to several factors such as poor dispersion and interfacial load transfer, deficiencies during processing, poor alignment, poor load transfer to the interior of filler bundles and the fractal nature of filler clusters. Therefore when the nanocomposites are exposed to liquid media, the degradation of mechanical properties is unavoidable unless the above-stated factors are otherwise.

\section{References}

1 A. J. Crosby and J. Lee, Polym. Rev., 2007, 47, 217-229.

2 D. R. Paul and L. M. Robeson, Polymer, 2008, 49, 3187-3204.

3 K. Friedrich and A. K. Schlarb, Tribology of polymeric nanocomposites: friction and wear of bulk materials and coatings, Elsevier, 2011, vol. 55.

4 A. Bouty, L. Petitjean, C. Degrandcourt, J. Gummel, P. Kwaśniewski, F. Meneau, F. Boué, M. Couty and J. Jestin, Macromolecules, 2014, 47, 5365-5378.
5 P. Bindu and S. Thomas, J. Phys. Chem. B, 2013, 117, 1263212648.

6 A. C. Balazs, T. Emrick and T. P. Russell, Science, 2006, 314, 1107-1110.

7 G. Schmidt and M. M. Malwitz, Curr. Opin. Colloid Interface Sci., 2003, 8, 103-108.

8 F. Gao, Mater. Today, 2004, 7, 50-55.

9 J. Njuguna, K. Pielichowski and S. Desai, Polym. Adv. Technol., 2008, 19, 947-959.

10 J. Njuguna, K. Pielichowski and S. Desai, Polym. Adv. Technol., 2010, 947-959.

11 E. P. Gellert and D. M. Turley, Composites, Part A, 1999, 30, 1259-1265.

12 A. Kootsookos and A. P. Mouritz, Compos. Sci. Technol., 2004, 64, 1503-1511.

13 K. Berketis, D. Tzetzis and P. J. Hogg, Mater. Des., 2008, 29, 1300-1310.

14 G. Huang and H. Sun, Mater. Des., 2007, 28, 1647-1650.

15 P. Neogi and G. Zahedi, Ind. Eng. Chem. Res., 2014, 53, 672677.

16 L. F. Henry, Polym. Eng. Sci., 1974, 14, 167-176.

17 L. Andena, L. Castellani, A. Castiglioni, A. Mendogni, M. Rink and F. Sacchetti, Eng. Fract. Mech., 2013, 101, 33-46.

18 R. Ollier, E. Rodriguez and V. Alvarez, Composites, Part A, 2013, 48, 137-143.

19 P. Patel, Environmental Stress Cracking In Thermoplastics Polyurethane, Loughborough University, 1982.

20 A. Blaga and R. S. Yamasaki, J. Mater. Sci., 1973, 8, 654-666.

21 M. S. Saharudin, A. Jumahat, A. Z. A. Kahar and S. Ahmad, Appl. Mech. Mater., 2013, 393, 88-93.

22 J. Jansen, The plastics killer, 2004.

23 J. M. Sadler, F. R. Toulan, G. R. Palmese and J. J. La Scala, J. Appl. Polym. Sci., 2015, 132.

24 A. Parashar and P. Mertiny, Procedia Eng., 2011, 10, 455459.

25 N. N. Bonnia, eXPRESS Polym. Lett., 2010, 4, 55-61.

26 J. K. Fink, Reactive Polymers Fundamentals and Applications, 2008, 1-67.

27 D. C. Wright, Environmental stress cracking of plastics, iSmithers Rapra Publishing, 1996.

28 W. L. Hawkins, Polymer degradation and stabilization, Springer Science \& Business Media, 2012, vol. 8.

29 J. K. Pandey, K. Raghunatha Reddy, A. Pratheep Kumar and R. P. Singh, Polym. Degrad. Stab., 2005, 88, 234-250.

30 J. R. White and A. Turnbull, J. Mater. Sci., 1994, 29, 584-613.

31 P. R. Lewis, Eng. Failure Anal., 2009, 16, 1816-1824.

32 J. B. P. Soares, R. F. Abbott and J. D. Kim, J. Polym. Sci., Part B: Polym. Phys., 2000, 38, 1267-1275.

33 G. Schellenberg and J. Fienhold, Polym. Eng. Sci., 1998, 38. 34 J. George, S. S. Bhagawan and S. Thomas, Compos. Sci. Technol., 1998, 58, 1471-1485.

35 M. Jawaid and H. P. S. Abdul Khalil, Carbohydr. Polym., 2011, 86, 1-18.

36 M. L. Chan, K. T. Lau, T. T. Wong and F. Cardona, Appl. Surf. Sci., 2011, 258, 860-864.

37 C. Zilg, R. Thomann, J. Finter and R. Mülhaupt, Macromol. Mater. Eng., 2000, 280-281, 41-46. 
38 X. Kornmann, H. Lindberg and L. A. Berglund, Polymer, 2001, 42, 4493-4499.

39 S. Sinha Ray and M. Okamoto, Prog. Polym. Sci., 2003, 28, 1539-1641.

40 K. Friedrich, J. Mater. Sci., 1981, 16, 3292-3302.

41 L. M. Robeson, Polym. Eng. Sci., 2013, 53, 453-467.

42 H. Voss and J. Kargerkocsis, Int. J. Fatigue, 1988, 10, 3-11.

43 A. Pegoretti and T. Ricco, Compos. Sci. Technol., 1999, 59, 1055-1062.

44 E. Pisanova, S. Zhandarov, E. Mäder, I. Ahmad and R. J. Young, Composites, Part A, 2001, 32, 435-443.

45 A. M. Skudra, Strength of fibrous composites, 1974, vol. 8.

46 A. Arbelaiz, B. Fernández, G. Cantero, R. Llano-Ponte, A. Valea and I. Mondragon, Composites, Part A, 2005, 36, 1637-1644.

47 W. Hufenbach, R. Böhm, M. Thieme, A. Winkler, E. Mäder, J. Rausch and M. Schade, Mater. Des., 2011, 32, 1468-1476. 48 C. Santulli, J. Mater. Sci., 2007, 42, 3699-3707.

49 J. Gustin, A. Joneson, M. Mahinfalah and J. Stone, Compos. Struct., 2005, 69, 396-406.

50 M. Cheng, W. Chen and T. Weerasooriya, J. Eng. Mater. Technol., 2005, 127, 197.

51 J. A. Bencomo-Cisneros, A. Tejeda-Ochoa, J. A. GarcíaEstrada, C. A. Herrera-Ramírez, A. Hurtado-Macías, R. Martínez-Sánchez and J. M. Herrera-Ramírez, J. Alloys Compd., 2012, 536, S456-S459.

$52 \mathrm{H}$. Ku, H. Wang, N. Pattarachaiyakoop and M. Trada, Composites, Part B, 2011, 42, 856-873.

53 R. J. Young and P. A. Lovell, Introduction to polymers, CRC press, 2011.

54 W. Miller, Z. Ren, C. W. Smith and K. E. Evans, Compos. Sci. Technol., 2012, 72, 761-766.

55 G. Williams, R. Trask and I. Bond, Composites, Part A, 2007, 38, 1525-1532.

56 D. F. Williams, A. McNamara and R. M. Turner, J. Mater. Sci. Lett., 1987, 6, 188-190.

57 S. Pimenta and S. T. Pinho, Waste Manag., 2011, 31, 378392.

58 G. M. Jenkins and F. X. de Carvalho, Carbon, 1977, 15, 3337.

59 A. Rasheed and F. A. Khalid, IOP Conf. Ser.: Mater. Sci. Eng., 2014, 60, 012009.

60 H. Pihtili, Eur. Polym. J., 2009, 45, 149-154.

61 J. L. Thomason and M. A. Vlug, Composites, Part A, 1996, 27, 477-484.

$62 \mathrm{~J}$. Thomason, Glass fibre sizings: a review of the scientific literature, Amazon Media EU, 2012.

63 T. Starr, Glass-fibre Directory and Databook, Springer Science \& Business Media, 1996.

64 E. K. Gamstedt, L. A. Berglund and T. Peijs, Compos. Sci. Technol., 1999, 59, 759-768.

$65 \mathrm{~J}$. Wei, T. Vo and F. Inam, RSC Adv., 2015, 5, 73510-73524.

66 F. Inam, B. R. Bhat, T. Vo and W. M. Daoush, Ceram. Int., 2014, 40, 3793-3798.

67 T. K. Das and S. Prusty, Polym.-Plast. Technol. Eng., 2013, 52, 130227104444003.
68 H. Kim, A. A. Abdala and C. W. MacOsko, Macromolecules, 2010, 43, 6515-6530.

69 R. Verdejo, M. M. Bernal, L. J. Romasanta and M. A. LopezManchado, J. Mater. Chem., 2011, 21, 3301-3310.

70 A. K. Geim and K. S. Novoselov, Nat. Mater., 2007, 6, 183191.

71 K. Yang, L. Feng, H. Hong, W. Cai and Z. Liu, Nat. Protoc., 2013, 8, 2392-2403.

72 A. K. Geim, Science, 2009, 324, 1530-1534.

73 V. Singh, D. Joung, L. Zhai, S. Das, S. I. Khondaker and S. Seal, Prog. Mater. Sci., 2011, 56, 1178-1271.

74 S. Ansari and E. P. Giannelis, Polym. Sci., 2009, 888-897.

75 Y. R. Lee, A. V. Raghu, H. M. Jeong and B. K. Kim, Macromol. Chem. Phys., 2009, 210, 1247-1254.

76 T. Ramanathan, A. A. Abdala, S. Stankovich, D. A. Dikin, M. Herrera-Alonso, R. D. Piner, D. H. Adamson, H. C. Schniepp, X. Chen, R. S. Ruoff, S. T. Nguyen, I. A. Aksay, R. K. Prud'Homme and L. C. Brinson, Nat. Nanotechnol., 2008, 3, 327-331.

77 S. Stankovich, D. A. Dikin, G. H. B. Dommett, K. M. Kohlhaas, E. J. Zimney, E. A. Stach, R. D. Piner, S. T. Nguyen and R. S. Ruoff, Nature, 2006, 442, 282-286.

78 Y. Xu, Y. Wang, J. Liang, Y. Huang, Y. Ma, X. Wan and Y. Chen, Nano Res., 2009, 2, 343-348.

79 F. Inam, Biology, 2012, 11-13.

80 F. Inam, D. W. Y. Wong, M. Kuwata and T. Peijs, J. Nanomater., 2010, 2010, 1-12.

81 F. Inam, A. Heaton, P. Brown, T. Peijs and M. J. Reece, Ceram. Int., 2014, 40, 511-516.

82 F. Inam and T. Peijs, Applied Science and Technology, 2007, 44, 38-44.

83 F. Inam, H. Yan, D. D. Jayaseelan, T. Peijs and M. J. Reece, J. Eur. Ceram. Soc., 2010, 30, 153-157.

84 N. G. Sahoo, S. Rana, J. W. Cho, L. Li and S. H. Chan, Prog. Polym. Sci., 2010, 35, 837-867.

85 S. Chatterjee, F. Nafezarefi, N. H. Tai, L. Schlagenhauf, F. A. Nüesch and B. T. T. Chu, Carbon, 2012, 50, 5380-5386.

86 V. Mirjalili, M. Yourdkhani and P. Hubert, Nanotechnology, 2012, 23, 315701.

87 B. Milsom, G. Viola, Z. Gao, F. Inam, T. Peijs and M. J. Reece, J. Eur. Ceram. Soc., 2012, 32, 4149-4156.

88 F. Inam, Development of Ceramic-Carbon Nanotube (CNT) Nanocomposites, 2009.

89 T. Y. Tsai, M. J. Lin, Y. C. Chuang and P. C. Chou, Mater. Chem. Phys., 2013, 138, 230-237.

90 A. Afzal, H. M. Siddiqi, N. Iqbal and Z. Ahmad, J. Therm. Anal. Calorim., 2013, 111, 247-252.

91 M. Manitiu, S. Horsch, E. Gulari and R. M. Kannan, Polymer, 2009, 50, 3786-3796.

92 J. Dusza, G. Blugan, J. Morgiel, J. Kuebler, F. Inam, T. Peijs, M. J. Reece and V. Puchy, J. Eur. Ceram. Soc., 2009, 29, 31773184.

93 F. Inam, H. Yan, T. Peijs and M. J. Reece, Compos. Sci. Technol., 2010, 70, 947-952.

94 F. Inam, T. Peijs and M. J. Reece, J. Eur. Ceram. Soc., 2011, 31, 2853-2859. 
95 D. W. Schaefer and R. S. Justice, Macromolecules, 2007, 40, 8501-8517.

96 M. Ho, H. Wang, J.-H. Lee, C. Ho, K. Lau, J. Leng and D. Hui, Composites, Part B, 2012, 43, 3549-3562.

97 S. H. Aziz and M. P. Ansell, Compos. Sci. Technol., 2004, 64, 1219-1230.

98 H. Dhakal, Z. Zhang and M. Richardson, Compos. Sci. Technol., 2007, 67, 1674-1683.

99 Z. Leman, S. M. Sapuan, A. M. Saifol, M. A. Maleque and M. Ahmad, Mater. Des., 2008, 29, 1666-1670.

100 J. Mogea, B. Seibert and W. Smits, Agroforestry Systems, 1991, 13, 111-129.

101 D. Bachtiar, S. M. Sapuan, E. S. Zainudin, A. Khalina and K. Z. M. Dahlan, IOP Conf. Ser.: Mater. Sci. Eng., 2010, 11, 012012.

102 M. R. Ishak, S. M. Sapuan, Z. Leman, M. Z. Rahman, U. M. Anwar and J. P. Siregar, Carbohydr. Polym., 2013, 91, 699-710.

103 T. H. Nam, S. Ogihara, N. H. Tung and S. Kobayashi, Composites, Part B, 2011, 42, 1648-1656.

104 A. Nigrawal, S. C. Prajapati, R. Sharma and N. Chand, Instrum. Sci. Technol., 2011, 18, 725-736.

105 T. Munikenche Gowda, A. C. B. Naidu and R. Chhaya, Composites, Part A, 1999, 30, 277-284.

106 D. Plackett, T. L. Andersen, W. B. Pedersen and L. Nielsen, Compos. Sci. Technol., 2003, 63, 1287-1296.

107 T. Nishino, K. Hirao, M. Kotera, K. Nakamae and H. Inagaki, Compos. Sci. Technol., 2003, 63, 1281-1286.

108 A. Keller, Bastfaserverstärkte, Biology, 1999, 1503, 261-266. 109 R. M. Kozłowski and M. Mackiewicz-Talarczyk, Handbook of Natural Fibres, 2012.

110 P. Wambua, J. Ivens and I. Verpoest, Compos. Sci. Technol., 2003, 63, 1259-1264.

111 M. Wollerdorfer and H. Bader, Ind. Crops Prod., 1998, 8, 105-112.

112 K. Oksman, M. Skrifvars and J. F. Selin, Compos. Sci. Technol., 2003, 63, 1317-1324.

113 J. F. Timmerman, B. S. Hayes and J. C. Seferis, Compos. Sci. Technol., 2002, 62, 1249-1258.

114 J. R. Potts, D. R. Dreyer, C. W. Bielawski and R. S. Ruoff, Polymer, 2011, 52, 5-25.

115 J. H. Park and S. C. Jana, Polymer, 2003, 44, 2091-2100.

116 S. Y. Fu, X. Q. Feng, B. Lauke and Y. W. Mai, Composites, Part B, 2008, 39, 933-961.

117 L. Tb and N. Le, J. Appl. Polym. Sci., 1970, 14, 1449-1471.

118 S. Ahmed and F. R. Jones, J. Mater. Sci., 1990, 25, 49334942.

119 J. N. Coleman, U. Khan, W. J. Blau and Y. K. Gun'ko, Carbon, 2006, 44, 1624-1652.

120 V. G. Grassi, M. F. Dal Pizzol, M. M. C. Forte and S. C. Amico, J. Appl. Polym. Sci., 2011, 121, 1697-1706.

121 J. Cho, F. Inam, M. J. Reece, Z. Chlup, I. Dlouhy, M. S. P. Shaffer and A. R. Boccaccini, J. Mater. Sci., 2011, 46, 4770-4779.

122 R. Rothon, Particulate-Filled Polymer Composites, 2003.

123 T. Mukherjee, M. Sani, N. Kao, R. K. Gupta, N. Quazi and S. Bhattacharya, Chem. Eng. Sci., 2013, 101, 655-662.
124 P. Pötschke, B. Krause, S. T. Buschhorn, U. Köpke, M. T. Müller, T. Villmow and K. Schulte, Compos. Sci. Technol., 2013, 74, 78-84.

125 J. Z. Liang, Composites, Part B, 2013, 51, 224-232.

126 B. Fiedler, F. H. Gojny, M. H. G. Wichmann, M. C. M. Nolte and K. Schulte, Compos. Sci. Technol., 2006, 66, 3115-3125.

127 H. Sun and B. Yang, Sci. China, Ser. E: Technol. Sci., 2008, 51, 1886-1901.

128 H. Palza, R. Vergara and P. Zapata, Compos. Sci. Technol., 2011, 71, 535-540.

129 S. Sprenger, J. Appl. Polym. Sci., 2013, 130, 1421-1428.

130 X. Chen and S. S. Mao, Chem. Rev., 2007, 107, 2891-2959.

131 C.-M. Chan, J. Wu, J.-X. Li and Y.-K. Cheung, Polymer, 2002, 43, 2981-2992.

132 S. Varghese, K. G. Gatos and A. A. Apostolov, Appl. Polym. Sci., 2003.

133 D. Kaempfer, R. Thomann and R. Mülhaupt, Polymer, 2002, 43, 2909-2916.

134 J. Zhou and J. P. Lucas, Compos. Sci. Technol., 1995, 53, 5764.

135 Z. Ji-Hua and Z. Mao-Sheng, J. Compos. Mater., 2004, 38, 779-790.

136 J. D. Garcia-Espinel, D. Castro-Fresno, P. Parbole Gayo and F. Ballester-Muñoz, Mater. Des., 2015, 66, 46-50.

137 L. Yan, N. Chouw and K. Jayaraman, Mater. Des., 2015, 71, 17-25.

138 H. Abral, D. Kadriadi, A. Rodianus, P. Mastariyanto, S. Arief, S. M. Sapuan, M. R. Ishak, et al., Mater. Des., 2014, 58, 125-129.

139 H. M. Akil, C. Santulli, F. Sarasini, J. Tirillò and T. Valente, Compos. Sci. Technol., 2014, 94, 62-70.

140 N. Rull, R. P. Ollier, G. Francucci, E. S. Rodriguez and V. A. Alvarez, J. Compos. Mater., 2015, 49, 1629-1637.

141 P. Joseph, M. S. Rabello, L. H. Mattoso, K. Joseph and S. Thomas, Compos. Sci. Technol., 2002, 62, 1357-1372.

142 S. Zainuddin, M. V. Hosur, Y. Zhou, A. Kumar and S. Jeelani, Mater. Sci. Eng., A, 2009, 507, 117-123.

143 W. Liu, S. V. Hoa and M. Pugh, Compos. Sci. Technol., 2005, 65, 2364-2373.

144 M. H. Gabr, N. T. Phong, M. A. Abdelkareem, K. Okubo, K. Uzawa, I. Kimpara and T. Fujii, Cellulose, 2013, 20, 819-826.

145 H. Alamri and I. M. Low, Polym. Compos., 2012, 33, 589-600. 146 K. P. Pramoda and T. Liu, J. Polym. Sci., Part B: Polym. Phys., 2004, 42, 1823-1830.

147 J. W. Rhim, S. I. Hong and C. S. Ha, LWT-Food Sci. Technol., 2009, 42, 612-617.

148 C. M. O. Müller, J. B. Laurindo and F. Yamashita, Ind. Crops Prod., 2011, 33, 605-610.

149 A. C. Karmaker, A. Hoffmann and G. Hinrichsen, J. Appl. Polym. Sci., 1994, 54, 1803-1807.

150 H. Alamri and I. M. Low, Mater. Des., 2012, 42, 214-222.

151 X. Liu, Q. Wu, L. A. Berglund, J. Fan and Z. Qi, Polymer, 2001, 42, 8235-8239.

152 W. J. Ward, G. L. Gaines, M. M. Alger and T. J. Stanley, J. Membr. Sci., 1991, 55, 173-180. 
153 A. Athijayamani, M. Thiruchitrambalam, U. Natarajan and B. Pazhanivel, Mater. Sci. Eng., A, 2009, 517, 344-353.

154 E. Moghbelli, R. Banyay and H.-J. Sue, Tribol. Int., 2014, 69, 46-51.

155 D. Wright, Failure of Plastics and Rubber Products, Rapra Technology Limited, 2006.

156 X. Li, Polym. Degrad. Stab., 2005, 90, 44-52.

157 C. H. Kim and J. R. Youn, Polym. Test., 2007, 26, 862-868.

158 P. Postawa and D. Kwiatkowski, Journal of Achievements in Materials and Manufacturing, 2006, 18, 171-174.

159 X. Chen, Y. C. C. Lam and D. Q. Q. Li, J. Mater. Process. Technol., 2000, 101, 275-280.

160 H. Zhou and D. Li, Int. J. Adv. Des. Manuf. Technol., 2005, 25, 700-704.

161 N. Pons, A. Bergeret, J. C. Benezet, L. Ferry and F. Fesquet, Polym. Test., 2011, 30, 310-317.

162 B. Borisova and J. Kressler, Macromol. Mater. Eng., 2003, 288, 509-515.

163 B. Borisova, Investigations on Environmental Stress Cracking Resistance of LDPE/EVA Blends, Martin-Luther-Universität Halle-Wittenberg, 2004.

164 N. Brown and X. Lu, Polymer, 1995, 36, 543-548.

165 Y.-L. Huang and N. Brown, Polymer, 1992, 33, 2989-2997.

166 A. L. Ward, X. Lu, Y. Huang and N. Brown, Polymer, 1991, 32, 2172-2178.

167 A. Evans, Int. J. Fract., 1974, 10, 251-259.

168 X. Lu, N. Brown and J. L. Bassani, Polymer, 1989, 30, 22152221.

169 A. Akdemir, N. Tarakcioglu and A. Avci, Stress, 2001, 32, 123-129.

170 J. K. Lim, Stress Corrosion Cracking, 2011.

171 R. D. Deanin and D. I. Hauser, Polym.-Plast. Technol. Eng., 1981, 17, 123-137.

172 J. C. Arnold, J. Mater. Sci., 1998, 33, 5193-5204.

173 A. N. Gent, J. Mater. Sci., 1970, 5, 925-932.

174 A. C. Knight, J. Polym. Sci., Part A: Gen. Pap., 1965, 3, 18451857.

175 C. M. Hansen, Polym. Degrad. Stab., 2002, 77, 43-53.

176 I. Widiastuti, I. Sbarski and S. H. Masood, J. Appl. Polym. Sci., 2013, 127, 2654-2660.

177 C. K. Kjellander, T. B. Nielsen, A. Ghanbari-Siahkali, P. Kingshott, C. M. Hansen and K. Almdal, Polym. Degrad. Stab., 2008, 93, 1486-1495.

178 P. Jawahar, R. Gnanamoorthy and M. Balasubramanian, Wear, 2006, 261, 835-840.
179 J. Crank, The mathematics of diffusion, Oxford university press, 1979.

180 S. Ramakrishna, J. Mayer, E. Wintermantel and K. W. Leong, Compos. Sci. Technol., 2001, 61, 1189-1224.

181 L. J. Lee, Ann. Biomed. Eng., 2006, 34, 75-88.

182 C. M. Brendel, Biocompatibility of Polymer Implants for Medical Applications, 2009.

183 Y. Ikada and H. Tsuji, Macromol. Rapid Commun., 2000, 21, 117-132.

184 A. I. Isayev, Encycl. Polym. Sci. Eng., 1987, 16, 747-767.

185 A. Lustiger and R. D. Corneliussen, J. Mater. Sci., 1987, 22, 2470-2476.

186 A. Lustiger and N. Ishikawa, J. Polym. Sci., Part B: Polym. Phys., 1991, 29, 1047-1055.

187 L. Alimi, K. Chaoui, W. Ghabeche and W. Chaoui, Mater. Tech., 2013, 101, 701.

188 A. Dashtizadeh, M. Abdouss, H. Mahdavi and M. Khorassani, Appl. Surf. Sci., 2011, 257, 2118-2125.

189 M. K. Byoung-Ho Choi, J. Weinhold and D. Reuschle, Polym. Eng. Sci., 2009, 47, 2085-2091.

190 J. M. Lagarón, N. M. Dixon, D. L. Gerrard, W. Reed and B. J. Kip, Macromolecules, 1998, 31, 5845-5852.

191 Y. Chen, J. Appl. Polym. Sci., 2014, 131, 1-8.

192 R. Farias, E. Canedo, R. Wellen and M. Rabello, Mater. Res., 2015, 18, 258-266.

193 E. T. Teofilo, S. M. L. Silva and M. S. Rabello, J. Appl. Polym. Sci., 2010, 118, 3089-3101.

194 Y. H. Muhammad, S. Ahmad, M. A. A. Bakar, A. A. Mamun and H. P. Heim, J. Reinf. Plast. Compos., 2015, 34, 896-906.

195 Y. Ruban, S. Mon and D. Roy, Appl. Nanosci., 2014, 233-240.

196 O. S. Sahin, A. Akdemir, A. Avci and L. Gemi, J. Reinf. Plast. Compos., 2008, 28, 2957-2970.

197 C. A. Wood and W. L. Bradley, Compos. Sci. Technol., 1997, 57, 1033-1043.

198 M. Khodabandelou, M. K. Razavi Aghjeh and M. Rezaei, Eng. Fract. Mech., 2009, 76, 2856-2867.

199 K. Cho, M. S. Lee and C. E. Park, Polymer, 1997, 38, 46414650.

200 F. Ramsteiner, G. McKee and M. Breulmann, Polymer, 2002, 43, 5995-6003.

201 D. Alperstein, D. Knani, N. Borchmann, M. Spekowius and C. Hopmann, Polym. Adv. Technol., 2014, 25, 1433-1438.

202 N. N. Bonnia, S. H. Ahmad, S. N. Surip, S. S. Nurul, H. N. Azlina and H. Anuar, Adv. Mater. Res., 2012, 576, 318-321. 